\title{
Modified Unified Theory of Acceptance and Use of Technology in Investigating Iranian Language Learners' Attitudes Toward Mobile Assisted Language Learning (MALL)
}

\author{
Rajab Esfandiari, ${ }^{1, *}$ and Fatemeh Sokhanvar ${ }^{2}$ \\ ${ }^{1}$ English Language Teaching, Department of English Language, Faculty of Humanities, Imam Khomeini International University, Qazvin, IR Iran \\ ${ }^{2}$ English Language Teaching, Department of English Language, Faculty of Accounting and Management, Islamic Azad University, Qazvin branch, Qazvin, IR Iran \\ "Corresponding author: Rajab Esfandiari, English Language Teaching, Department of English Language, Faculty of Humanities, Imam Khomeini International University, \\ Qazvin, IR Iran, E-mail: esfandiari@hum.ikiu.ac.ir
}

Received 2015 July 20; Revised 2015 December 30; Accepted 2015 December 24.

\begin{abstract}
Introduction: The modified unified theory of acceptance and use of technology (MUTAUT) was used in this mixed methods study to investigate language learners' attitudes toward mobile assisted language learning (MALL).

Methods: Two different student surveys were used to collect data quantitatively. The surveys consisted of 24 and 23 items, respectively, rated on a 6-point Likert scale. Reliability was estimated to be 0.92 and 0.95 , respectively. To collect data qualitatively, language learners were interviewed regarding their opinions on MALL. Standard multiple regression and descriptive statistics employing IBM SPSS version 21 were used to analyze the data.

Results: Analysis of quantitative data revealed that performance expectancy, effort expectancy, and perceived playfulness were significant predictors of the behavioral intention to use mobile devices, while self-management of learning and social influence were $\operatorname{not}(\mathrm{P}<0.001)$. Analysis of descriptive statistics from the second survey showed that language learners have totally positive attitudes toward effectiveness and satisfaction; however, their attitudes about usefulness were somewhat mixed. Analysis of qualitative data generally confirmed the quantitative results.

Conclusions: Language instructors should motivate students to use mobile devices to learn, become more autonomous language learners, and manage their own learning.
\end{abstract}

Keywords: Mobile Phone, Attitude, Intention, Technology

\section{Introduction}

Mobile devices are becoming increasingly popular among language learners $(1,2)$, making language learning more effective and faster (3). These devices include different kinds of mobile systems like mobile phones, smart phones, iPods, tablets, personal digital assistants (PDAs), and so on. Using a mobile device to learn a foreign language is called mobile assisted language learning (MALL), or m-learning (4-6).

In a recent study, Hwang et al. (7) investigated the role of mobile game-based activities in speaking and listening tasks. Results revealed that learners' speaking skills were developed while they played games on their mobile devices. Furthermore, participants had totally positive attitudes toward using these devices for learning. Hsu (8) explored the attitudes of 45 international foreign language learners toward mobile assisted language learning. According to the results of this study, participants held different perceptions toward mobile assisted language learning. In another study, Viberg and Gronlund (9) investigated learners' attitudes toward mobile assisted language learn- ing across cultures. Participants had positive attitudes toward mobile assisted language learning. Wang et al. (1) investigated the behavioral intention of university students toward mobile learning based on a modified version of the unified theory of acceptance and use of technology. Their results showed that performance expectancy, effort expectancy, social influence, self-management of learning, and perceived playfulness have a positive effect on individuals' behavioral intention to use mobile devices. In another study, Chen (2) examined the attitudes of language learners toward tablet PCs. The findings revealed that tablet computers are effective and easy to use tools. Moreover, participants were completely satisfied with using these devices for learning.

In Iran, some researchers have studied m-learning. Mansouri et al. (10) explored the attitudes of university students toward m-learning at Payamenoor University of Gonbad in Gonbad Kavus, Golestan. The results of this study revealed that $83.33 \%$ of students carried their mobile phones with them and used them during the day. The results also showed that students harbored no negative atti- 
tudes towards mobile learning and believed it could benefit them. Similar results were also obtained by Forooshani et al. (11), Morsaei et al. (12), and Yaghoubi and Baratali (13).

Abdekhoda et al. (14) investigated the determinants of acceptance of Information Technology (IT) among the health information management staff of Tehran University using the technology acceptance model. According to the results, perceived usefulness and ease of use are factors which determine the acceptance of IT among health information management staff. Therefore, it was suggested that perceived ease of use and usefulness be considered as important elements for IT designers. A similar study was done by Esmaeili et al. (15), who found a high positive correlation between perceived ease of use and users' intention. They concluded that the most important factor in the technology acceptance model is perceived ease of use.

Sadeghitabar et al. (16) evaluated factors affecting the implementation of mobile learning in continuing medical education programs using the theory of reasoned action (TRA) at Shahid Beheshti University of Medical Sciences, Tehran, Iran. Three hundred and thirty-three staff members participated in the study in which data was collected using a questionnaire. The results indicated that the intention of mobile learning correlated mostly with the mentality of mobile learning, tendency to mobile learning, and behavioral control, respectively. The researchers concluded that the learners' level of knowledge of mobile learning would be carefully examined before a mobile learning system was implemented.

Using a mixed methods study to investigate management students' satisfaction with mobile phones at Mehre Alborz higher education institute in Tehran, Sheikholeslami et al. (17) found that questionnaire analysis showed no statistically significant difference in using mobile phones on students' satisfaction; the results of interviews showed that students were satisfied with mobile phones when they were used to keep them informed about their class schedule or other similar purposes, but they were not satisfied with mobile phones when used to teach them content.

\subsection{Performance Expectancy (Effectiveness)}

Venkatesh et al. (18) described performance expectancy as the extent to which individuals believe that using different mobile devices will help them enhance their performance. According to Wang et al. (1), learners can benefit from using their mobile devices in their learning contexts. Previous studies have also shown that performance expectancy and learners' satisfaction might be related to each other $(19,20)$. Satisfaction with mobile devices helps learners achieve learning goals more quickly and more ef- fectively. Performance expectancy influences the attitudes of technology users (21).

\subsection{Effort Expectancy (Usability)}

According to Wang et al. (1), effort expectancy is perceived as whether mobile devices are easy to use for individuals. Previous research has revealed that effort expectancy is related to performance expectancy (22-26). Furthermore, it can be considered as a predictor of behavioral intention to use mobile devices $(1,27)$. Lin et al. (28) determined three individual differences that have positive relationships with effort expectancy: personal innovativeness, self-efficacy, and previous experience. According to the researchers, using these devices is simple for people with a high degree of self-efficacy. Moreover, individuals who have previous experience using a new mobile device are often more comfortable using these devices. The researchers concluded that people who are innovative are likely to take the initiative to try new technology.

\subsection{Social Influence}

Social influence is associated with the effect of society on individuals' intention to use mobile devices. According to Lin et al. (28), learners are more affected by their own classmates than their teachers and will use a mobile device if they have their friends' approval. Previous research has revealed that social influence might affect students' intention to use mobile devices $(29,30)$, and it affects individuals' intention to use technology $(1,31,32)$. According to Venkatesh et al. (18), social factors do not influence users in a voluntary context; however, they influence users who are in their first stages of experiencing new devices and those who are working in a mandatory context. The influence of society on users' actions is due to the factors of compliance, internalization, and identification.

\subsection{Self-Management of Learning}

Wang et al. (1) described self-management of learning as "the extent to which an individual feels he or she is self-disciplined and can engage in autonomous learning" (p. 100). According to Huang et al. (33), self-management of learning is related to self-supporting, individualistic, and unconventional learning. The researchers explored the effects of three constructs, perceived playfulness, selfmanagement of learning, and resistance to change mobile learning outcomes. Their results revealed that it is important to support individuals in an appropriate time in increasing opportunities to use mobile devices and in decreasing the effect of resistance to change people. Previous research has shown that self-management of learning has an important effect on individuals' learning outcomes (34). Furthermore, the results of many studies have 
revealed the significant influence of self-management of learning on users' intention to use mobile devices $(1,35-$ 39).

\subsection{Perceived Playfulness (Satisfaction)}

According to Wang et al. (1), perceived playfulness relates to concentration, curiosity, and enjoyment. Previous studies have shown that individuals with higher levels of perceived playfulness might interact with mobile devices and learn something about their interest (33). Perceived playfulness is associated with intrinsic motivation, and learners are more likely to be interested in an activity because they desire to do it (40). This factor was mostly studied with the technology acceptance model; as a result, it is considered one of the determinants of perceived ease of use (effort expectancy) (41-49).

As the discussed studies show, m-learning has been examined from different perspectives both in Iran and elsewhere. Some researchers have studied attitudes of learners toward different mobile devices for learning; other researchers have explored learners' attitudes toward using information technology and m-learning based on the technology acceptance model theory. Further studies have examined the effect of mobile devices on learning. However, using the modified unified theory of acceptance and use of technology to examine m-learning among learners of English as a foreign language is relatively unexplored. The present study, therefore, attempted to fill this gap. The present researchers also investigated the attitudes of language learners toward usability, effectiveness, and satisfaction toward mobile devices. To achieve the goals of the study, two research questions were proposed:

1) Are performance expectancy, effort expectancy, social influence, self-management of learning, and perceived playfulness significant predictors of behavioral intention to use mobile devices among Iranian EFL language learners?

2) What are Iranian EFL language learners' attitudes toward usability, effectiveness, and satisfaction with technology use and mobile devices for language learning?

\section{Methods}

A sequential explanatory mixed-methods design was used in this study. Data was collected both quantitatively and qualitatively. Quantitative data was collected using two questionnaires (described below). The first English questionnaire (See Appendix A) used in this study was that of Wang et al. (1). This questionnaire had six subscales: performance expectancy ( 4 items), effort expectancy ( 4 items), social influence ( 4 items), self-management of learning (4 items), perceived playfulness ( 5 items), and behavioral intention of the users ( 3 items). It contained 24 items on a 6-point Likert scale with ratings of strongly disagree (1), slightly disagree (2), disagree (3), agree (4), slightly agree (5), and strongly agree (6) and was administered to a group of 40 language learners with reliability estimates as shown in Table 1. The Cronbach's alpha for the modified unified theory of acceptance and use of technology questionnaire turned out to be 0.92 .

Table 1. Cronbach's Alpha for Different Subscales of Modified Unified Theory of Acceptance and Use of Technology Questionnaire

\begin{tabular}{lc}
\hline Subscales & Cronbach's alpha \\
\hline Behavioral intention & 0.71 \\
\hline Effort expectancy & 0.81 \\
\hline Performance expectancy & 0.81 \\
\hline Social influence & 0.84 \\
\hline Perceived playfulness & 0.76 \\
\hline Self-management of learning & 0.68 \\
\hline
\end{tabular}

The second English questionnaire (See Appendix B) used in this study was that of Chen (2). It was used to seek the attitudes of language learners toward usability, effectiveness, and satisfaction with mobile devices. The questionnaire contained 23 items rated on a 6-point Likert scale with strongly disagree (1), slightly disagree (2), disagree (3), agree (4), slightly agree (5), and strongly agree (6). It was administered to a group of 40 language learners with reliability estimates as shown in Table 2 . The Cronbach's alpha for the attitudinal questionnaire turned out to be 0.95 .

Table 2. Reliability Estimates for Different Subscales of the Attitudinal Questionnaire for the Second Questionnaire

\begin{tabular}{lc}
\hline Subscales & Cronbach's Alpha \\
\hline Effectiveness & 0.91 \\
Satisfaction & 0.91 \\
Usability & 0.75 \\
\hline
\end{tabular}

IMB SPSS version 21 was used to analyze the quantitative data, using standard multiple regression and descriptive statistics.

Language learners were chosen using convenience sampling and based on easy accessibility and availability. Initially, participants in this study included 350 language learners. However, only 320 language learners returned completed questionnaires. Out of these 320 language learners, 20 were excluded, because their surveys were incomplete (many items were blank). Therefore, only 
the questionnaires for 300 language learners were used for final data analysis.

Out of 300 language learners who completed the questionnaires, 60 agreed to be interviewed. The lead researcher contacted them individually one week later at the mobile phone numbers they had written on the questionnaires and arranged an interview, which was structured and included five questions closely related to the items on questionnaires A and B (See Appendix C). Interviewing took two weeks, because it was not possible for all language learners to attend interview sessions on the same day. Each language learner was briefed again on the objectives of the study, and the lead researcher assured participants that their responses would be kept confidential. Each structured interview lasted approximately ten minutes, and the language learners' responses were audio recorded since participants were not comfortable with video recording. Responses were transcribed and coded, central themes were identified, and, finally, similarities and differences were listed.

\section{Results}

\subsection{Quantitative Results}

Table 3 shows the participants' demographic information.

Table 3. Breakdown of Language Learners' Demographic Information

\begin{tabular}{l|c|c}
\hline \multirow{2}{*}{ Gender } & & No. (\%) \\
\hline \multirow{4}{*}{ Age } & Male & $100(33.3)$ \\
\cline { 2 - 3 } & Female & $200(66.7)$ \\
\cline { 2 - 3 } & $12-18$ & $185(61.7)$ \\
\cline { 2 - 3 } & $18-24$ & $71(23.7)$ \\
\cline { 2 - 3 } & $24-30$ & $25(8.3)$ \\
\hline \multirow{4}{*}{ Educational background } & $30-u p$ & $19(6.3)$ \\
\cline { 2 - 3 } & Student & $185(61.7)$ \\
\cline { 2 - 3 } & University student & $75(25.0)$ \\
\cline { 2 - 3 } & Other & $40(13.3)$ \\
\hline \multirow{2}{*}{ Language proficiency } & Elementary & $83(27.7)$ \\
\cline { 2 - 3 } & Intermediate & $145(48.3)$ \\
\cline { 2 - 3 } & Advanced & $72(24.0)$ \\
\hline
\end{tabular}

In this study, two research questions were formulated, the first of which examined predictors of behavioral intention to use mobile devices and the second explored language learners' attitudes toward mobile devices.

\subsection{Investigation of the First Research Question}

To answer the first research question (Are performance expectancy, effort expectancy, social influence, selfmanagement of learning and perceived playfulness significant predictors of behavioral intention to use mobile devices among Iranian EFL language learners?), a standard multiple regression was used. Based on the results shown in Table 4 the $R$ square value is 0.410 . This shows that our model explains $41 \%$ of variance in behavioral intention to use mobile devices.

The results of the ANOVA test (Table 5) shows that the predictive power of the model is statistically significant $(\mathrm{F}$ $(5,267)=37.150, \mathrm{P}<0.001)$.

\subsection{Dependent Variable: Behavioral Intention}

Predictors: Performance expectancy, effort expectancy, self-management of learning, social influence, perceived playfulness.

In Table 6 the largest beta value belongs to effort expectancy, indicating this factor makes the strongest contribution to explaining behavioral intention. After effort expectancy, performance expectancy and perceived playfulness make significant contributions to explaining behavioral intention. The researchers checked the Sig value for each independent variable. If it was less than 0.05 , the variable was considered to make a significant unique contribution to the prediction of the dependent variable. According to the results, performance expectancy, effort expectancy, and perceived playfulness make statistically significant contributions to the prediction of behavioral intention to use mobile devices.

It can be concluded that performance expectancy, effort expectancy, and perceived playfulness are significant predictors of behavioral intention, while social influence and self-management of learning are not.

\subsection{Investigation of Second Research Question}

To analyze the second research question (What are Iranian EFL language learners' attitudes toward usability, effectiveness, and satisfaction with the use of technology and mobile devices for language learning?), descriptive statistics such as frequencies and percentages were used. Participants had positive attitudes toward effectiveness and satisfaction; however, their attitudes toward usability were somewhat mixed. For Use 1 (40\%) and Use 2 (29.3\%), participants' attitudes were negative, because most of them strongly disagreed with these two statements. However, they had somewhat positive attitudes toward usability in the third statement, because they slightly agreed on this one (Use 3: 24.7\%). Participants held consistent attitudes toward effectiveness and satisfaction, because most 
Table 4. Model Summary for Predictors

\begin{tabular}{lcccc}
\hline Model & R & R Square & Adjusted R Square & Standard Error of Estimate \\
\hline $\mathbf{1}$ & 0.641 & 0.410 & 0.399 & 2.15411 \\
\hline
\end{tabular}

Table 5. ANOVA Test for Predictors

\begin{tabular}{|c|c|c|c|c|c|}
\hline Model & Sum of Squares & df & Mean Square & $\mathbf{F}$ & Sig \\
\hline Regression & 861.912 & 5 & 172.382 & 37.150 & $<0.001$ \\
\hline Residual & 1238.930 & 267 & 4.640 & & \\
\hline Total & 2100.842 & 272 & & & \\
\hline
\end{tabular}

Table 6. Coefficients for Predictors

\begin{tabular}{|c|c|c|c|c|c|}
\hline \multirow{2}{*}{$\begin{array}{l}\text { Model } \\
1\end{array}$} & \multicolumn{2}{|c|}{ Unstandardized Coefficient } & \multicolumn{3}{|c|}{ Standardized Coefficient } \\
\hline & B & Std. Error & Beta & $\mathbf{t}$ & Sig \\
\hline Constant & 4.352 & 0.857 & & 5.78 & $<0.001$ \\
\hline Performance Expectancy & 0.230 & 0.049 & 0.309 & 4.710 & $<0.001$ \\
\hline Effort Expectancy & 0.237 & 0.049 & 0.326 & 4.864 & $<0.001$ \\
\hline Perceived Playfulness & 0.081 & 0.035 & 0.136 & 2.310 & 0.022 \\
\hline Self-management of learning & -0.010 & 0.036 & -0.014 & -0.271 & 0.786 \\
\hline
\end{tabular}

of them slightly agreed or agreed on the remaining statements which were related to effectiveness and satisfaction.

The mean for each item across all language learners was calculated (Tables 7 - 9). Mean values also confirmed language learners' positive attitudes toward effectiveness, satisfaction, and Use 3, but negative attitudes toward Use 1 and Use 2. Higher mean values indicated more agreement, implying positive attitudes, but lower mean values denoted less agreement, suggesting negative attitudes.

Table 7. Mean Vales for Use Subscale

\begin{tabular}{lccc}
\hline & Use1 & Use 2 & Use 3 \\
\hline Number of respondents & 297 & 294 & 295 \\
Missing & 3 & 6 & 7 \\
Mean & 2.7845 & 2.9184 & 3.4915 \\
\hline
\end{tabular}

\subsection{Qualitative Results}

To obtain more in-depth information, a structured interview was carried out with 60 language learners. The results generally supported the quantitative findings. The first interview question (effectiveness) was whether mobile devices enhance language learners' language perfor- mance. Out of 60 language learners, 40 of them conveyed that mobile devices are useful tools for language learning. For example, one language learner stated, "Mobile devices help me learn English more quickly and effectively." Twenty language learners mentioned that using mobile devices helped them improve their vocabulary learning. One language learner asserted, "I use mobile devices to find new words from the dictionary." Furthermore, 10 participants stated that watching movies or listening to music on mobile devices helped them improve their language performance. One learner remarked, "I usually listen to English music on my mp3 player, and sometimes I look at the lyrics while I am listening to improve my language." Three other answers to the first interview question given by language learners were:

- "Yes, for example, I listen to the pronunciation of each word in the dictionary and I just use this application for my learning.

- Yes, I use my mobile device for finding new words in the dictionary.

- Yes, for finding the answers of the questions more quickly and to avoid complications.

The second interview question (social influence) was concerned with the way language learners and teachers affect learners to use their mobile mobiles for language 
Table 8. Mean Values for Effectiveness Subscale

\begin{tabular}{lcccccccccc}
\hline & E1 & E2 & E3 & E4 & E5 & E6 & E7 & E8 & E9 & E10 \\
\hline Number of respondents & 296 & 295 & 295 & 294 & 293 & 297 & 297 & 297 & 297 & 297 \\
Missing & 4 & 5 & 5 & 6 & 7 & 3 & 3 \\
Mean & 4.24 & 4.19 & 4.09 & 3.79 & 4.27 & 4.21 & 4.24 & 4.06 & 4.22 & 4.17 \\
\hline
\end{tabular}

Table 9. Mean Values for Satisfaction Subscale

\begin{tabular}{|c|c|c|c|c|c|c|c|c|c|c|}
\hline & s1 & S2 & $\mathrm{S}_{3}$ & S4 & S5 & 56 & $S_{7}$ & s8 & S9 & S10 \\
\hline Number of respondents & 293 & 294 & 292 & 294 & 295 & 294 & 295 & 295 & 292 & 292 \\
\hline Missing & 7 & 6 & 8 & 6 & 5 & 6 & 5 & 5 & 8 & 8 \\
\hline Mean & 4.46 & 4.36 & 4.31 & 4.34 & 4.28 & 4.38 & 4.47 & 4.47 & 4.54 & 4.54 \\
\hline
\end{tabular}

learning. Out of 60 language learners, 45 did not think they were influenced by other people, not even their teachers, and their classmates usually did not encourage them to use mobile devices for language learning. Ten language learners mentioned that most teachers and classmates are not familiar with applications provided for language learners to enhance their learning, and some of them are not even interested in using mobile devices for teaching and learning. For example, one language learner stated, "They did not encourage me to use mobile devices for learning, because they themselves are not familiar with devices or applications." Three other answers given by language learners to the second interview question were:

- No, it did not happen for me.

- No, they did not encourage me to use mobile devices for learning, because they themselves are not familiar with devices or applications.

- No, they just motivate us to use dictionaries from mobile devices.

The third interview question (satisfaction) was related to the feeling of language learners when they use mobile devices for learning. According to the responses, 50 language learners were satisfied with using mobile devices for their language learning, and seven students felt anxious or uneasy when using these devices. One language learner said, "I really enjoy using mobile devices for my learning, because I can access the information much easier and faster". Based on the findings, convenient access to information and ease of use of these devices result in pleasure for learners. Three other statements made by language learners in response to the third interview question were:

- I enjoy using mobile devices for learning.

- I do not enjoy it very much and I do not feel anything at all; sometimes I feel that it is really boring.

- I enjoy using mobile devices, because they are easy to use and I can access the information faster.
The fourth interview question (usability) was whether language learners' interaction with mobile devices for language learning is clear and understandable. Forty participants believed that mobile devices are easy to use. One language learner stated, "Most mobile devices are easy to use, and it does not take much time to learn how to work with these devices." Ten language learners thought it would be easy for them to use mobile devices if they had support from a group or an organization which designs different kinds of applications for them. One language learner stated, "If there were an organization which could help users with the difficulties we encounter while using applications for education, learning language or even other subjects from these devices would be much easier." Four others added that direct guidance from experienced users would help them access information much more easily and faster than usual. One of the language learners said, "I think if experienced users support us, we can manage using these devices and it would be easier." Three other responses to the fourth interview question given by language learners were:

- It is not easy; it depends on the applications.

- It is easy; I think if experienced users support us we could manage using these devices and it would be easier.

- It is easier than using books for finding words.

The last interview question (self-management of learning) concerned whether mobile devices help language learners to be independent language learners. According to the responses, 25 language learners believed that they could manage their own learning and did not need their teachers for support, because they can easily access the information they need using their mobile devices and the Internet. One language learner said, “I don't think that I need a teacher's help while I am using my device for learning. With the internet available in many places, we can access the information when we need it." In contrast, 35 of the students thought that having a teacher is necessary for learn- 
ing a foreign language because of the support they provide and because students can ask questions whenever they encounter a problem regarding their language learning. One language learner stated, "I do not think that it would be possible for me to learn English without my teacher's help. I use mobile devices for learning, but sometimes we cannot solve our problems without any help." Three other responses given by language learners to the last interview question were:

- No, I think it distracts language learners.

- No, I think that for language learning you need to be present in different classes and activities.

- Yes, when I am using mobile devices I feel that I do not need anybody's help.

\section{Conclusions}

The findings of this research revealed that performance expectancy, effort expectancy, and perceived playfulness are significant predictors of behavioral intention to use mobile devices, but self-management of learning and social influence are not. Effort expectancy was found to be the strongest predictor of all. Participants had totally positive attitudes toward effectiveness and satisfaction; however, their attitudes about usability were mixedthey had positive attitudes toward Use 1 and Use 2, but negative attitudes toward Use 3.

The results regarding performance expectancy are in line with those of previous studies $(1,18,21,27)$. In a study conducted by Wang et al. (1), performance expectancy was found to be a significant predictor and the strongest determinant of users' behavioral intention to use mobile devices. Abdekhoda et al. (14) determined that usefulness (performance expectancy) had a significant influence on IT acceptance among university staff. The current study also found that effort expectancy is the strongest predictor of language learners' behavioral intention to use mobile devices. This finding is in line with that of both Abdekhoda et al. (14) and Esmaeili et al. (15), who found that perceived ease of use (effort expectancy) is related to the acceptance and intention of the participants to use the technology. The findings are also consistent with those of the previous studies $(1,24)$.

Perceived playfulness turned out to be a significant predictor of language learners' behavioral intention to use mobile devices. This finding is in line with that of previous studies (1,35-39). Melendez et al. (50) found that perceived playfulness has a strong impact on the learner's intention to use a particular mobile device.

Self-management of learning and social influence were not significant predictors of behavioral intention to use mobile devices in this study. The findings of this research do not support those of previous studies (1, 29-37). Qualitative analysis results generally confirmed this finding. As presented in the previous section, the majority of language learners (45 out of 60) stated that they were not heavily influenced by teachers to use mobile devices, because language teachers were not familiar with mobile devices, did not know how to use them, mostly asked language learners to use dictionaries in those devices, and believed they would distract language learners from language learning. Most language learners (35 out of 60) preferred teachers over mobile devices, because they were available and could provide help whenever language learners needed it.

The results of this study indicate that language learners had positive attitudes about effectiveness and satisfaction; however, their attitudes toward usability were mixed. The results of language learners' attitudes about effectiveness and satisfaction are in line with previous literature (2, $14,15,17,51,52$ ). Sheikholeslami et al. (17) showed in their qualitative results that students were satisfied with mobile phones when they used them to keep them informed about their class schedules or other similar purposes. The findings about language learners' attitudes toward usability, however, were contrary to those of previous studies (2, $14,15,51,52)$, suggesting that language learners are willing to use mobile devices on different occasions and are completely satisfied with the functions of these devices.

Pedagogical implications: The findings of this research might have some pedagogical implications. The more help language learners can get help from mobile devices, the easier it is for them to use mobile devices, and the more playable they are, the more language learners intend to use mobile devices for learning. Therefore, language teachers should invest in intrinsically motivating language learners to use mobile devices and raising language learners' consciousness regarding the different functions and applications these mobile devices offer. Producers could also design and produce materials for mobile devices, thereby making them more exciting, more technology-related, and more personalized.

Limitations and future research: The findings of this study are based on the attitudes of a particular group of language learners in Iran; therefore, the findings cannot be generalized to a large international population. The perceptions of language teachers according to the modified unified theory of acceptance and use of technology were not analyzed; future research can be conducted to evaluate the perceptions of both language learners and instructors based on this theory and to compare the results of both groups. Convenience sampling was used for this study. This kind of sampling has some limitations; therefore, random sampling is recommended for use in future research. 


\section{Supplementary Material}

Supplementary material(s) is available here.

\section{Acknowledgments}

The authors wish to thank the language learners who participated in this study.

\section{Footnotes}

Conflict of Interest: In this study, the authors did not receive any financial support from any institute.

Authors' Contribution: The authors contributed to the production of this paper in the following ways: study design and concept: Rajab Esfandiari and Fatemeh Sokhanvar; analysis and interpretation of data: Rajab Esfandiari; drafting of the manuscript: Fatemeh Sokhanvar; critical revision of the manuscript for important intellectual content: Rajab Esfandiari; statistical analysis: Rajab Esfandiari and Fatemeh Sokhanvar.

\section{References}

1. Wang YS, Wu MC, Wang HY. Investigating the determinants and age and gender differences in the acceptance of mobile learning. BrJEduc Technol. 2009;40(1):92-118. doi: 10.1111/j.1467-8535.2007.00809.x.

2. Chen XB, Kessler G. Action research tablets for informal language learning: Student usage and attitudes. Language Learn Technol. 2013;17(1):20-36.

3. Cotter JJ, Gendron T, Kupstas P, Tartaglia A, Will L. Perceived Benefits of Mobile Learning Devices for Doctoral Students in a School of Allied Health Professions. J Allied Health. 2015;44(4):29E-33E.

4. Kukulska-Hulme A. Will mobile learning change language learning?. ReCALL. 2009;21(02):157. doi: 10.1017/s0958344009000202.

5. Montrieux H, Vanderlinde R, Schellens T, De Marez L. Teaching and Learning with Mobile Technology: A Qualitative Explorative Study about the Introduction of Tablet Devices in Secondary Education. PLoS One. 2015;10(12):e0144008. doi: 10.1371/journal.pone.0144008. [PubMed: 26641454].

6. Kukulska-Hulme A, Shield L. An overview of mobile assisted language learning: From content delivery to supported collaboration and interaction. ReCALL. 2008;20(03) doi: 10.1017/s0958344008000335.

7. Hwang WY, Shih TK, Ma ZH, Shadiev R, Chen SY. Evaluating listening and speaking skills in a mobile game-based learning environment with situational contexts. Comput Assist Language Learn. 2016;29(4):639-57.

8. Hsu L. English as a foreign language learners' perception of mobile assisted language learning: a cross-national study. Comput Assist Language Learn. 2013;26(3):197-213. doi: 10.1080/09588221.2011.649485.

9. Viberg O, Gronlund A. Cross-cultural analysis of users' attitudes toward the use of mobile devices in second and foreign language learning in higher education: A case from Sweden and China. Comput Educ. 2013;69:169-80. doi: 10.1016/j.compedu.2013.07.014.

10. Mansouri S, Kaghazi B, Khormali N. A survey the views of the students of Gonbad Payam Noor University to mobile learning. The first Conference of mobile value-added services in Iran. Tehran. Centre of Technology Studies of Sharif University; .
11. Forooshani N, Khosravipour B, Yaghoubi J. A survey the views of the Agriculture organization experts of Khuzestan Province toward mobile educational systems. The fourth national conference and the first international conference on e-learning. Tehran. University of science and technology; .

12. Morsaei S, Yaghoubi J, Rajaei Y. A survey the views of the Managers of agricultural cooperatives toward mobile learning. International Conference on Electronic Citizenship and Mobile. .

13. Yaghoubi J, Baratali J. A survey of the role of mobile technologies in offering of electronic administrative services to the rural (Case study: Zanjan). The Second International Conference on Electronic Administrative System. Tehran. Center of Tapko Scientific Conferences; .

14. Abdekhoda M, Ahmadi M, Hossini AF, Prikhani E, Farhadi A. Factors affecting information technology acceptance by health information management (HIM) staff of Tehran university of medical sciences' hospitals based on the technology acceptance model (TAM) in 2011. J Payavard Salamat. 2013;7(4):287-98.

15. Esmaeili M, Eshlaghi AT, Ebrahimi AP, Esmaieli R. Study on feasibility and acceptance of implementation of Technology Acceptance Model of Davis in staff of Shahid Beheshti University of Medical Sciences. Pajoohandeh J. 2013;18(1):40-5.

16. Sadeghitabar P, Shobeiri SM, Zakeri Z. Evaluation of the factors affecting implantation of mobile learning at continuing medical education program, using the theory reasoned action. Interdisciplinar J Virt Learn Med Sci. 2015;6(2):11-9.

17. Sheikholeslami V, Mohammad Eslami N, Gholipoor A. The investigation of mobile learning effectiveness on organizational behavior training. Manag Res. 2014;27(8):35-56.

18. Venkatesh V, Morris MG, Davis GB, Davis FD. User acceptance of information technology: Toward a unified view. MIS Q. 2003:425-78.

19. Roca JC, Chiu CM, Martínez FJ. Understanding e-learning continuance intention: An extension of the Technology Acceptance Model. Int J Human Comput Stud. 2006;64(8):683-96. doi: 10.1016/j.ijhcs.2006.01.003.

20. Sun PC, Tsai RJ, Finger G, Chen YY, Yeh D. What drives a successful e-Learning? An empirical investigation of the critical factors influencing learner satisfaction. Comput Educ. 2008;50(4):1183-202. doi: 10.1016/j.compedu.2006.11.007.

21. Liao HL, Lu HP. The role of experience and innovation characteristics in the adoption and continued use of e-learning websites. Comput Educ. 2008;51(4):1405-16. doi: 10.1016/j.compedu.2007.11.006.

22. Zhou T. Exploring Mobile User Acceptance Based on UTAUT and Contextual Offering. Proceedings of the 2008 International Symposium on Electronic Commerce and Security. China. IEEE Press; 2008. pp. 241-5.

23. Entsieh AA, Emmelin M, Pettersson KO. Learning the ABCs of pregnancy and newborn care through mobile technology. Glob Health Act. 2015;8(1):29340. doi: 10.3402/gha.v8.29340.

24. Pavon F, Brown I. Factors influencing the adoption of the World Wide Web for job-seeking in South Africa. SA J Inf Manag. 2010;12(1) doi: 10.4102/sajim.v12i1.443.

25. Zhou T, Lu Y, Wang B. Integrating TTF and UTAUT to explain mobile banking user adoption. Comput Human Behav. 2010;26(4):760-7. doi 10.1016/j.chb.2010.01.013.

26. Chen KY, Chang ML. User acceptance of 'near field communication' mobile phone service: an investigation based on the 'unified theory of acceptance and use of technology' model. Service Industries J. 2013;33(6):609-23. doi: 10.1080/02642069.2011.622369.

27. Carlsson C, Carlsson J, Hyvonen K, Puhakainen J, Walden P, editors. Adoption of mobile devices/services-searching for answers with the UTAUT. System Sciences, 2006. HICSS'06. Proceedings of the 39th Annual Hawaii International Conference on. 2006; IEEE; p. 132a.

28. Lin S, Zimmer JC, Lee V. Podcasting acceptance on campus: The differing perspectives of teachers and students. Comput Educ. 2013;68:41628. doi: 10.1016/j.compedu.2013.06.003.

29. Venkatesh V, Davis FD. A Theoretical Extension of the Technology Acceptance Model: Four Longitudinal Field Studies. Manag Sci. 2000;46(2):186-204. doi: 10.1287/mnsc.46.2.186.11926. 
30. Moore GC, Benbasat I. Development of an Instrument to Measure the Perceptions of Adopting an Information Technology Innovation. Inf Systems Res. 1991;2(3):192-222. doi: 10.1287/isre.2.3.192.

31. Balavivekanandhan A, Arulchelvan S. A Study on Students Acquisition of IT Knowledge and Its Implication on M-Learning. The Scientific World Journal. 2015;2015:1-11. doi: 10.1155/2015/248760.

32. Lopez-Nicolas C, Molina-Castillo FJ, Bouwman H. An assessment of advanced mobile services acceptance: Contributions from TAM and diffusion theory models. Inf Manag. 2008;45(6):359-64. doi: 10.1016/j.im.2008.05.001.

33. Huang RT, Jang SJ, Machtmes K, Deggs D. Investigating the roles of perceived playfulness, resistance to change and self-management of learning in mobile English learning outcome. Br J Educ Technol. 2012;43(6):1004-15. doi: 10.1111/j.1467-8535.2011.01239.x.

34. Abar B, Loken E. Self-regulated learning and self-directed study in a pre-college sample. Learn Individ Differ. 2010;20(1):25-9. doi: 10.1016/j.lindif.2009.09.002. [PubMed: 20161484].

35. Huang JH, Lin YR, Chuang ST. Elucidating user behavior of mobile learning. Electron Lib. 2007;25(5):585-98. doi: 10.1108/02640470710829569.

36. Davis FD, Bagozzi RP, Warshaw PR. Extrinsic and Intrinsic Motivation to Use Computers in the Workplace1. J Appl Soc Psychol. 1992;22(14):1111-32. doi: 10.1111/j.1559-1816.1992.tb00945.x.

37. Igbaria M, Guimaraes T, Davis GB. Testing the Determinants of Microcomputer Usage via a Structural Equation Model. J Manag Inf Systems. 2015;11(4):87-114. doi: 10.1080/07421222.1995.11518061.

38. Venkatesh V, Brown SA. A Longitudinal Investigation of Personal Computers in Homes: Adoption Determinants and Emerging Challenges. MIS Q. 2001;25(1):71. doi: 10.2307/3250959.

39. Yu J, Ha I, Choi M, Rho J. Extending the TAM for a t-commerce. Inf Manag. 2005;42(7):965-76. doi:10.1016/j.im.2004.11.001.

40. Moon JW, Kim YG. Extending the TAM for a World-Wide-Web context Inf Manag. 2001;38(4):217-30. doi:10.1016/s0378-7206(00)00061-6.

41. Day-Black C, Merrill EB. Using Mobile Devices in Nursing Education. ABNF J. 2015;26(4):78-84. [PubMed: 26665501].

42. Liao $\mathrm{CH}$, Tsou CW. User acceptance of computer-mediated communi- cation: The SkypeOut case. Expert Systems Appl. 2009;36(3):4595-603. doi: 10.1016/j.eswa.2008.05.015.

43. Tao YH, Cheng CJ, Sun SY. What influences college students to continue using business simulation games? The Taiwan experience. Comput Educ. 2009;53(3):929-39. doi:10.1016/j.compedu.2009.05.009.

44. Terzis V, Economides AA. Computer based assessment: Gender differences in perceptions and acceptance. Comput Human Behav. 2011;27(6):2108-22. doi:10.1016/j.chb.2011.06.005.

45. Celik H. What determines Turkish customers' acceptance of internet banking?. Int J Bank Market. 2008;26(5):353-70. doi: $10.1108 / 02652320810894406$.

46. Hong JC, Hwang MY, Hsu HF, Wong WT, Chen MY. Applying the technology acceptance model in a study of the factors affecting usage of the Taiwan digital archives system. Comput Educ. 2011;57(3):2086-94. doi:10.1016/j.compedu.2011.04.011.

47. Venkatesh V, Bala H. Technology Acceptance Model 3 and a Research Agenda on Interventions. Decision Sci. 2008;39(2):273-315. doi: 10.1111/j.1540-5915.2008.00192.x.

48. Davis R, Wong D. Conceptualizing and Measuring the Optimal Experience of the eLearning Environment. Decision Sci J Innov Educ. 2007;5(1):97-126. doi: 10.1111/j.1540-4609.2007.00129.x.

49. Sun H, Zhang P. An exploration of affect factors and their role in user technology acceptance: Mediation and causality. J Am Soc Inf Sci Technol. 2008;59(8):1252-63. doi:10.1002/asi.20819.

50. Padilla-Melendez A, del Aguila-Obra AR, Garrido-Moreno A. Perceived playfulness, gender differences and technology acceptance model in a blended learning scenario. Comput Educ. 2013;63:306-17. doi: 10.1016/j.compedu.2012.12.014.

51. Basoglu EB, AKDEMIRO. A comparison of undergraduate students' English vocabulary learning: Using mobile phones and flash cards. Turk Online J Educ Technol. 2010;9(3).

52. Ozok AA, Benson D, Chakraborty J, Norcio AF. A Comparative Study Between Tablet and Laptop PCs: User Satisfaction and Preferences. Int J Human Comput Interact. 2008;24(3):329-52. doi: $10.1080 / 10447310801920524$. 